\title{
Analysis of Farmers' Intention to Accept Wetland Compensation Policy: China Farmers' Perspective
}

\author{
HONGGEN Zhu' ${ }^{1}$, HONGNAN You ${ }^{1}$, LANYUAN Kang ${ }^{1}$, ZHENGFEI Guan ${ }^{2}$ \\ ${ }^{1}$ Jiangxi Agriculture University, Nanchang, China \\ ${ }^{2}$ Food and Resource Economics Department, University of Florida, Gainesville, USA
}

Keywords: Wetland restoration protection; Wetland compensation Policy; Technology Acceptance Model; Farmers.

\begin{abstract}
Wetland compensation is one important measure for wetland restoration and protection, while establishment and implement of Wetland Compensation Policy (WCP) is the dominating step. So understanding the intention to accept this policy among farmers is very important. Economic models do not fully explain farmers' behavior intention with regards to Wetland Compensation Policy acceptance. Hence, based on Technology Acceptance Model (TAM), this paper investigates factors influencing farmers' intention to accept Wetland Compensation Policy in Poyang Lake region in China. The results of the research showed that perceived usefulness (PU), perceived ease of use (PEU) have significant positive impacts on farmers' intention to accept WCP. In addition, the most salient modification, compared with earlier TAM models, is that perceived of trust (PT) plays an important role in farmers' intention to accept WCP. Age, gender and education are also introduced as moderator variables which affect the farmers' acceptance intention by means of PU, PT and PEU. This study extends the application of the TAM to agriculture policy domain to promote further investigation of factors affecting the acceptance and usage of agriculture policy such as WCP by farmers, policy-makers, and agriculture researchers.
\end{abstract}

\section{INTRODUCTION}

Wetland is not only a valuable natural resource for human survival, but also one of the most important environments (Kingsford, 2012), which is known as the "kidney" of the earth and the "gene pool" of species. Meanwhile, as an important guarantee of the sustainable development of the economy, society and environment, the protection and restoration of wetland becomes a significant issue. While timely adoption and appropriate use of easily and widely available Wetland Compensation Policy in wetland protection is an important step that may help in enhancing wetland restoration activities and hence contributes to promote ecology-environment sustainable development.

Poyang Lake is the largest freshwater lake in China, and plays a crucial ecological role in maintaining China's Ecosystem. But in recent years, the shrinking of wetlands is becoming more and more serious, in effort to address the problems of Poyang Lake's wetland; government has already taken some measures, including returning farmland to Lake Wetland and building new towns in order to settle down the people who will emigrate from the wetland area. Meanwhile, different levels of wetland protection and management institutions are also established.

As the protection of wetland in Poyang Lake region in China depends on Wetland Compensation Policy and farmers, much attention needs to be paid to the farmers who are the main body during the Wetland Compensation Policy implementation. Against this backdrop this paper aims primarily to investigate the factors influencing the intention to accept Wetland Compensation Policy among the farmers in Poyang Lake region in China. The underlying purpose of doing so is to allow a better understanding of how to provide useful Wetland Compensation Policy to the farmers. 


\section{LITERATURE REVIEW}

Many scholars have spent decades identifying impact factors of acceptance or adaption of agriculture technologies. Technology acceptance and adoption research has developed several competing and complementary models each with a different set of acceptance determinants. Technology acceptance model, TAM, is one of the most popular models in the field of general technology acceptance models. An extensive body of research has demonstrated the explanatory power of TAM in use of various technologies in agriculture field. For example, Anne M A et al (2005) reported that attitudes of confidence toward using the precision agriculture technologies, perceptions of net benefit, farm size and farmer educational levels positively influenced the intention to adopt precision agriculture technologies. Olusegun F et al (2008) found that perceived ease of use and perceived usefulness are important constructs when determining user attitudes towards knowledge management system (KMS) in agriculture extension services. Jingjing Zhang et al(2010) suggested that income, attitude, risk preference, perceived usefulness, searching motivation and experience affect farmers' agricultural information acceptance directly. Friederike et al (2009) analysis the factors of farmers' acceptance to organic Certification System and result demonstrate that the perceived usefulness of the certification system is an important impact factor. Holger S et al (2007) investigated the acceptance of the organic certification system in Germany basis on TAM.

Understanding the perceptions and attitudes of farmers can lead to understanding why farmers adopt technologies beyond the economic benefit. Derived from the current researches and frameworks, what can be viewed is that TAM is normally used as the foundation model in which researchers expand this model by incorporating proper variables based on the technology under study. Hence, in our study, our aim is to decide whether the characteristics of farmers have an effect on the acceptance of Wetland Compensation Policy (WCP). Based on the aim above, modifications have been made to extended TAM models by introducing new constructs of PT together with PU, PEU. Hence, this study will use the research model for WCP acceptance.

\section{HYPOTHESIS DEVELOPMENT}

In this study, behavioral intention has been used to indicate the actual influence on acceptance of Wetland Compensation Policy (WCP). It is mentioned in many research studies that the behavioral intentions will have a positive and direct influence on usage behavior (Venkatesh et al, 2003). For brevity, in current study the behavioral intention to accept Wetland Compensation Policy will be used to measure the actual accept of Wetland Compensation Policy in China.

H1: Perceived usefulness has a positive effect on farmers' acceptance intention to Wetland Compensation Policy.

H2: PEU has positive effect on farmers' acceptance intention to Wetland Compensation Policy. H3: PT has positively effect on farmers' acceptance intention to Wetland Compensation Policy.

\subsection{Moderator variable}

Several studies (Mohammed A et al, 2012) have shown that Gender, age, education were posited to mediate the impact of key constructs on acceptance intention. For example, Venkatesh, M and Ackerman (2000) asserted that the males were greatly affected by attitude towards the adoption of a new technology; while the females were more influenced by subjective norm and perceived behavioral control. Björn $\mathrm{N}$ and Ralf $\mathrm{P}$ (2013) concluded that the inclusion of the socio-demographic (age, gender, income, education) moderating variables is valuable and is clearly able to increase the adjusted coefficient of UTAUT. In this research, by examining the moderating effects of gender, practitioners and researchers will be able to have better understanding and insight on how gender, age and education influences the farmers' intention to accept Wetland Compensation Policy. We hypothesize that Gender, age and education have significant moderating effects on farmers' acceptance intention to Wetland Compensation Policy. 


\subsection{Control variable}

There are a good number of studies describing the importance of the demographic contexts in use and adoption of new technology. These demographic variables have the potential to confound the influence of determinants on a technology adoption but they do not drive the grounded theory. In this study, gender, age, and education are taken as the control variables. Currently, studies on the differences related to the age, gender and education from the technology adoption perspective especially Wetland Compensation Policy are indeed dearth. Thus, the findings from this study will surely contribute to the body of knowledge with regards to their influences on the acceptance intention to Wetland Compensation Policy. We hypothesize that the acceptance intention would be higher for male farmers as their risk taking are stronger since they will be likely to accept uncertain and new things like Wetland Compensation Policy. Besides that, farmers with higher educational level normally will secure more knowledge and better capability making Wetland Compensation Policy more acceptable to them. Lastly, older farmers are expected to have fewer tendencies to accept Wetland Compensation Policy as they are risk aversion.

\section{SAMPLING AND DATA}

The dataset used in the present paper comes from the Farmers' Survey in Poyang Lake region in China, which was conducted jointly by the School of Economic and Management of Jiang Xi Agriculture University and the Total Survey Team of Jiangxi province of China Statistics Bureau between October and December 2013. The survey covered 1200 households, 59 villages, 11 counties in Poyang Lake region. We gave out 1,200 questionnaires. Subsequently, and got 1,009 effective questionnaires, the proportion of the actual effective questionnaires to the total questionnaires reach to $84.1 \%$.

To capture the latent variables of research model, different measurement scales that had partly been tested in previous were used. PU, PEU, and PT questionnaire item was scored on a five-point Likert scale ( $1=$ strongly disagree; $2=$ disagree; $3=$ neutral; $4=$ agree; and $5=$ strongly agree). As to dependent variable, we asked participants to describe their attitudes toward acceptance intention to Wetland Compensation Policy on a five-point scale (1=strongly unwillingness; $2=$ unwillingness; $3=$ neutral; 4 = willingness; and $5=$ strongly willingness). Factor analysis was performed to assess the validity of the construct and OLS regression analysis were employed to analyze the data. We provide the summary statistics among the variables in Table 1.

Table 1.Means, standard deviation and correlation among the studied variables

\begin{tabular}{|c|c|c|c|c|c|}
\hline Variable & $\begin{array}{l}\text { Description of } \\
\text { variables }\end{array}$ & Frequency & $\%$ & Mean & SD \\
\hline \multirow{4}{*}{ Age } & $\begin{array}{l}30 \text { years and } \\
\text { below }\end{array}$ & 119 & 11.8 & \multirow[b]{3}{*}{44.9} & \multirow[b]{3}{*}{118} \\
\hline & 31-44 years & 406 & 40.2 & & \\
\hline & $45-59$ years & 354 & 35.1 & & \\
\hline & $\begin{array}{l}60 \text { years and } \\
\text { above }\end{array}$ & 130 & 12.9 & \multirow{3}{*}{0.82} & \multirow{3}{*}{0.4} \\
\hline \multirow[t]{2}{*}{ Gender } & $\begin{array}{l}\text { female } \\
\text { male }\end{array}$ & $\begin{array}{l}250 \\
759\end{array}$ & $\begin{array}{l}24.8 \\
75.2\end{array}$ & & \\
\hline & illiteracy & 198 & 19.6 & & \\
\hline \multirow{4}{*}{$\begin{array}{c}\text { Educatio } \\
\text { n level }\end{array}$} & $\begin{array}{l}\text { Primary } \\
\text { school }\end{array}$ & 272 & 27.0 & \multirow{4}{*}{2.7} & \multirow{4}{*}{1.2} \\
\hline & Middle school & 251 & 24.9 & & \\
\hline & High school & 196 & 19.4 & & \\
\hline & $\begin{array}{l}\text { College and } \\
\text { above }\end{array}$ & 92 & 9.1 & & \\
\hline
\end{tabular}

\section{RESULTS}

The results of our study are presented below in two steps. On the one hand, we examine the 
validity of our constructs and make factor analysis. On the other hand, we present the regression model: the coefficients of all variables in all three models (TAM) with and without moderating and control variables.

\subsection{Factor analysis}

Statistical Package for Social Sciences (SPSS) version 12 was used as the analysis tool.

Reliability is determined by Cronbach's coefficient alpha $(\alpha)$, a popular method for measuring reliability; We calculate this number automatically by using statistical package SPSS and as a result this package was used to measure the reliability of the main constructs of the questionnaire. the reliability scores of all constructs were found to exceed the threshold; all measures demonstrated good levels of reliability (greater than 0.85 ).

Items in the questionnaire were relevant to factor analysis. To determine the underlying structure, the correlation matrix was initially examined to determine how appropriate it was for factor analysis. We ran Bartlett's test for sphericity and Kaiser-Meye-Olkin (KMO) measure of sampling adequacy and showed that the Kaiser-Meyer-Oklin (KMO) value was 0.808, higher than the recommended minimum of 0.6 , indicating that the sample size was adequate for applying factor analysis. In addition, value of the test statistic for sphericity on the basis of a Chi-squared transformation of the determinant of correlation matrix was large. Bartlett's test of sphericity was significant, supporting the factor ability of correlation matrix and associated significance level was extremely small (0.000).

We chose to use principal component analysis as the method of extracting factors since it enables us to uncover latent variables in our survey. The number of extracted factors was decided based on the latent root and scree test criterions (Hair Jr JF et al, 1998). Three factors had eigen values over 1. And three factors were chosen for the final analysis. The cumulative variance extracted by the three factors was $76.228 \%$. The extracted factors were then rotated using variance maximizing method (Varimax). The factors identified were PU, PEU and PT. In current study, the dependent variables WCP refer to the acceptance intention to Wetland Compensation Policy which is used to measure the actual accept of Wetland Compensation Policy in China.

\subsection{Regression analysis}

The regression analysis was conducted to reveal how different factors affect the acceptance intention to Wetland Compensation Policy. In the first research model (TAM without moderator effects and control variables), Model (1) shows that all coefficients of PU, PT and PEU are statistically significant at $1 \%$ level and have a high influence on farmers' acceptance intention to WCP. The overall model was also statistically significant (Adjusted $\mathrm{R}^{2}=0.084, \mathrm{p}<0.001$ ), implying that model (1) has accounted for $8.4 \%$ of the variance in the dependent variable. In the second model, control socio-demographic variables (including education, gender and age) were added to estimate its effect on the outcome. Model (2) shows that PU, PT and PEU are still statistically significant at $1 \%$ level and have a high influence on acceptance intention of WCP. Both Gender and Age are significant at 5\% level, and coefficient of variable presenting age is negative, while age square is also significant at $5 \%$ level and positive, implying that the relationship between farmers' age and acceptance intention to WCP is U-shaped. The overall model was also statistically significant (Adjusted $\mathrm{R}^{2}=0.090, \mathrm{p}<0.001$ ), implying that model (2) has accounted for $9.0 \%$ of the variance in the dependent variable. In the third model (TAM with moderating socio-demographic variables); these relationships are moderated by education, gender, and age. Accordingly, 9 interaction terms related to demographic variables were added to the analysis. Result of model (3) suggests that only a minority of all coefficients used is significant because a high number of moderating variables often go in hand with lower statistical power. This phenomenon is observable in prior IS research as well (Venkatesh et al, 2003, where most of the interaction terms were non-significant). However, we can observe that age has a negative direct effect on acceptance intention to WCP. Moreover, age negatively influences the relationship between PT and acceptance intention to WCP. Several coefficients in the third model can be considered significant (PU, PT, PEU, Age, Age square, and Gender). Moreover, the overall model (3) was also statistically 
significant (Adjusted $\mathrm{R}^{2}=0.095, \mathrm{p}<0.001$ ), implying that our socio-demographic moderating variables results in an explanation of almost $9.5 \%$ of the variance in the data. To analyze whether the increase of $\mathrm{R}^{2}$ was significant, we conducted a further model comparison. Hence, we computed an F-statistic and compared it with the corresponding critical values following the work of Chin (2010). Increases of $\mathrm{R}^{2}$ from models (1) (0.084) to model (3) (0.095) were significant. Hence, we conclude that the inclusion of the socio-demographic moderating variables is valuable. While Increases of $\mathrm{R}^{2}$ from models (1) (0.084) to model (2) (0.090) was significant, implying that the inclusion of control socio-demographic variables is also valuable.

In addition, we run a correlation analysis to further test our hypotheses. The results indicate that PU $(\mathrm{p}<.05)$, PEU $(\mathrm{p}<.05)$ and PT $(\mathrm{p}<.01)$ are positively correlated with acceptance intention to WCP. In sum, PU, PT and PEU clearly have a positive effect on farmers' acceptance intention to Wetland Compensation Policy. Based on our data analysis H1, H2 and H3 were supported statistically.

\begin{tabular}{|c|c|c|c|}
\hline \\
\hline & Model1 & Model 2 & Model 3 \\
\hline PU & $0.169^{* * *}$ & $0.158^{* * *}$ & $0.370^{* *}$ \\
\hline PT & $0.169^{* * *}$ & $0.165^{* * *}$ & $0.340^{* *}$ \\
\hline PEU & $0.129^{* * *}$ & $0.132^{* * *}$ & 0.149 \\
\hline Age & & $-0.035^{* *}$ & $-0.030^{* *}$ \\
\hline Age2 & & $0.0001^{* *}$ & $0.0001^{* *}$ \\
\hline Gender & & $0.138^{* *}$ & $0.125^{*}$ \\
\hline Education & & 0.007 & 0.005 \\
\hline Age* PU & & & -0.003 \\
\hline Age* PT & & & $-0.006^{* *}$ \\
\hline Age* PEU & & & -0.002 \\
\hline Gender * PU & & & -0.042 \\
\hline Gender * PT & & & 0.035 \\
\hline Gender * PEU & & & -0.018 \\
\hline Education * PU & & & -0.014 \\
\hline Education * PT & & & 0.027 \\
\hline Education * PEU & & & 0.032 \\
\hline constant & $3.549^{* * *}$ & $4.227^{* * *}$ & 4.128 \\
\hline $\mathrm{F}$ & $31.783^{* * *}$ & $15.198^{* * *}$ & $7.619^{* * * *}$ \\
\hline Adjusted R2 & 0.084 & 0.090 & 0.095 \\
\hline
\end{tabular}

\section{DISCUSSION AND FINDINGS}

This study examines the influence of PEU, PU and PT on acceptance intention to WCP. As expected, the results of the regression analysis conducted on the factors indicate that PT, PU and PEU were found to be the most influential factors explaining the acceptance intention to Wetland Compensation

Policy. It shows that PU, PEU and PT have positive relation with acceptance intention to WCP supporting the hypotheses.

When Wetland Compensation Policy is perceived as useful, farmers' acceptance intention to WCP would be greater. Likewise farmers are likely to accept Wetland Compensation Policy when it is easy to understand and be implemented. This shows that farmers anchor their Wetland Compensation Policy acceptance intention to the beneficial outcomes and ease of use process of the policy. Although WCP is beneficial and ease of use, however farmers are still reluctant to accept the compensation policy because of the insufficient trust associated with government. Farmers are not ready to take any uncertainty to accept the Wetland Compensation Policy.

In addition, an extension of TAM technology acceptance theories by a set of socio-demographic 
variables can provide a better explanation of Wetland Compensation Policy by the farmers. On the one hand, an extension in terms of the three socio-demographic variables of age, gender, and education are clearly able to increase the adjusted coefficient of determination for TAM (adjusted $\mathrm{R}^{2}, 0.084$ without moderating effects to 0.095 with moderating effects) and (adjusted $\mathrm{R}^{2}, 0.084$ without control variables to 0.090 with control variables). Accounting for the fact that these three socio-demographic constructs are measured with one item each, we argue that the socio-demographic perspective is valuable (significantly increased explanatory power) as an extension of TAM for explaining acceptance intention to Wetland Compensation Policy by farmers. On the other hand, a significant extension of the theoretical model and the model coefficients (hypotheses) results habitually in a decrease of the number of significant individual coefficients (Venkatesh et al, 2003; Brown \& Venkatesh, 2005). Still, research model (3) in table 5 reveals interesting insights. The coefficient of age is negative statistically significant at $5 \%$ level and the coefficient of age square is positive effect statistically significant at $5 \%$ level, this finding offers evidence for a U-shaped relationship between age and acceptance intention of Wetland Compensation Policy, implying that middle-age famers are less likely to accept Wetland Compensation Policy, while the younger farmer and elderly farmers are more likely to accept Wetland Compensation Policy. Apparently, age exerts a significant age-moderated effect of PU and PT in model (3) of the Order Logistic Model (age $\times \mathrm{PU},-0.010, \mathrm{P}<0.1$ significance level; age $\times \mathrm{PT}$, $-0.013, \mathrm{P}<0.1$ significance level), indicating that for elderly farmers, age will decrease the effect of PU and PT on acceptance intention to Wetland Compensation Policy.

\section{IMPLICATIONS}

This research has examined three determinants that may influence acceptance intention to WCP and discovered that PU, PT and PEU have significant effects towards acceptance intention to WCP. It has offered both theoretical and practical contributions in terms of acceptance intention to WCP.

\subsection{Theoretical implications}

This study has assessed the associations between acceptance intention to WCP and the three hypotheses of the framework involving PU, PEU, and PT. The suggested framework in this research is based on the TAM models used which was derived from the past studies. Hence, by using the FA, OLS regression, the validity of this model is enhanced and validated and may give a better understanding and insights in the determinants that contribute to the acceptance intention. With the inclusion of age, gender and education moderating effects and control variables of age, gender and education, the model has contributed significantly in extending the traditional TAM model. It may also present a better depiction because it has been implemented in an Asian developing country .These findings may be used as a guideline for other developing countries, particularly those which share similar socio-economic and technological background and plan to establish their own policy on wetland compensation. The proposed model also makes important contributions to the emerging literature on Wetland Compensation Policy.

\subsection{Policy implications}

Government may consider these factors especially PU, PT and PEU being three main determinants when designing and upgrading their Wetland Compensation Policy.

On the one hand, government should take into consideration about the potential benefits it offers for their lives and production in practice factor by presenting more elements of compensation that include cash compensation, loans preference, providing occupation training and free technology advisory services, providing job opportunity, farmland compensation, project investment support and preferential tax policy. On the other hand, it is also crucial for government to provide services that are farmer-friendly and easy to understand contents of compensation policy as illustrated by the importance of PEU. To boost the level of PEU, policy-maker should notice that compensation policy contents should be operated easily and farmers may better understand the policy, and compensation measures should be more in line with farmers' actual lives and production activities. 
Trust between government and farmers is one of the important influential factors, implying that enhancement of trust between government and farmers are also very important. However, building trust between government and farmers is much more difficult than providing benefits to farmers. Therefore, government needs to search for trust-improving strategies that might assist in inspiring high confidence in potential farmers. In addition, this study suggests that government could develop trust-building mechanisms to attract farmers, such as statements of guarantee and long-term farmer service.

A surprising finding of the significant moderating effect and control effect of age, gender and education will enable practitioners and stakeholders to have better decision making processes in terms of age, gender and education differences. They should apply a different ways and strategy to cater to the needs of different personality farmers. Besides that, based on the fact that there were confounding effects of control variables (i.e. age, gender) on acceptance intention to Wetland Compensation Policy, government should also use a different strategy across various farmers segmentations.

\section{CONCLUSION}

This study applies presently amended TAM model on farmer acceptance intention to Wetland Compensation Policy in China. Based on the data collected and results of the analysis, it can be concluded that PU, PEU and PT are important determinants of Wetland Compensation Policy acceptance. Age has a U-shaped relationship with farmers' acceptance intention to Wetland Compensation Policy as well as a significant moderating impact on the relationship between PU and PT.

In addition, there is still room for further investigation into the acceptance intention to Wetland Compensation Policy. The replication of this study on a wider scale with more farmers and with different countries is essential for further generalization of the findings. By using a longitudinal study in the future, we could investigate our research model in different time periods and make comparisons, thus providing more insights into the acceptance of Wetland Compensation Policy. To be more precise and convincing, our work will continue and new findings will be anticipated.

\section{Acknowledgement}

This work was supported by the National Natural Science Foundation of China under Grant No. 41261106 and Grant No. 41361007; and Social Science Foundation of China under Grant No. 13\&ZD160; and Science and Technology Project of the Department of Education of Jiangxi Province under Grant No. GJJ12217); and Social Science Foundation of Jiangxi Province under Grant No. 11YJ36.

\section{References}

[1]. Anne,M.A et al. 2005. Producers' Perceptions and Attitudes toward Precision Agriculture Technologies. Computers and Electronics in Agriculture(48): 256-271.

[2]. Brown ,Sa \& Venkatesh ,V.2005.Model of Adoption of Technology in Households: a Baseline Model Test and Extension Incorporating Household Life Cycle. MIS Quarterly29(3):399-426.

[3]. Brown, Sa \&Venkatesh, V.2010.Predicting Collaboration Technology Use: Integrating Technology Adoption and Collaboration Research. Journal of Management Information System27(2): 9-53.

[4]. Friederike, A. H \& Achim,S.2009. Evaluation and Reliability of the Organic Certification System: Perceptions by Farmers in Latin America. Sustainable Development. (17):311-324.

[5]. Hair, J.J et al. Multivariate Data Analysis, Upper Saddle River: Prentice-Hall NJ. 1998. 
[6]. Holger, Schulze et al. Acceptance of the Organic Certification System by Farmers in Germany. 17th Annual IAMA World Forum and Symposium Conference. June 2007.

[7]. Jingjing Zhang et al.2010.Farmers' Information Acceptance Behavior in China. African Journal of Agricultural Research 5(3):217-221.

[8]. Kaiser,H.1976.An Index of Factorial Simplicity. Psychometrika39(1):31-36.

[9]. Kingsford ,R,T.2011. Conservation Management of Rivers and Wetlands under Climate Change- a synthesis. Marine and Freshwater Research 62, 217-222.

[10]. Mohammad. A.H. \& Mohammed Quaddus.2010.IS Design Science Research, IFIP AICT (318):179-191.

[11]. Mohammed Alshehri et al.2012.Analysis of Citizens' Acceptance for E-government Services: Applying the UTAUT Model. IADIS International Conferences Theory and Practice in Modern Computing and Internet Applications and Research. 69-76.

[12]. Olusegun Folorunso \& Shawn Oluwafemi Ogunseye. 2008. Applying an Enhanced Technology Acceptance Model to Knowledge Management in Agricultural Extension Services. Data Science Journa7(22):31-45.

[13]. Venkatesh,V.2000.Determinants of Perceived Ease of Use: Integrating Control, Intrinsic Motivation and Emotion into the Technology Acceptance Model. Information System Research 11(4):342-365.

[14]. Venkatesh, V et al.2003.User Acceptance of Information Technology: toward a Unified View. MIS Quarterly27 (3):425-478. 